\title{
Morphometric Analysis on Shape Transition during Growth of the Red Snapper (Lutjanus campechanus, Poey, 1860)
}

\section{Elvia Teresa Mendoza-Barrera, María Eugenia Vega-Cendejas, Monica Améndola-Pimenta, Rossanna Rodríguez-Canul ${ }^{*}$}

Departamento de Recursos del Mar. Centro de Investigación y de Estudios Avanzados del IPN (CINVESTAV-IPN)-Unidad Mérida. Carr. Mérida, Yucatán, México

Email: *rossana.rodriguez@cinvestav.mx

How to cite this paper: Mendoza-Barrera, E.T., Vega-Cendejas, M.E., Améndola-Pimenta, M. and Rodríguez-Canul, R. (2018) Morphometric Analysis on Shape Transition during Growth of the Red Snapper (Lutjanus campechanus, Poey, 1860). Open Journal of Marine Science, 8, 407-430.

https://doi.org/10.4236/ojms.2018.84023

Received: August 15, 2018

Accepted: October 15, 2018

Published: October 18, 2018

Copyright (c) 2018 by authors and Scientific Research Publishing Inc. This work is licensed under the Creative Commons Attribution International License (CC BY 4.0).

http://creativecommons.org/licenses/by/4.0/

\section{(c) (i) Open Access}

\begin{abstract}
The red snapper Lutjanus campechanus (Poey, 1860) has a high commercial value that sustains an important fishery in Mexico. In this study, the patterns in morphological variations from early juvenile to adult stages were assessed by geometric methods (GM) in 194 organisms. Changes in shape were more evident and rapid in the early juvenile stage and decreased during adulthood. The principal components analysis of shape (Relative Warp Analysis, or RWA) identified size and body depth as the main sources of variance associated to both juvenile and adult organisms. The outline of the head and the tail showed the most noticeable differences following the ontogenic pathway visualized by thin-plate splines indicating that the ontogenetic pathway of the upper half and the lower half of the dorsal head profile (DHP) are in relatively opposite directions than those from the tail that bends ventrally. The Two-Block Partial Least Square analysis (2B-PLS) and their CR coefficients showed that the two modules had a moderate linear trend $(\mathrm{p}=0.001)$. Although the blocks have morphological changes at different rates, there is a moderate synchrony in growth by modules. This study is the first to report the use of geometrical morphometry in L. campechanus in Mexico.
\end{abstract}

\section{Keywords}

Lutjanus campechanus, Ontogeny, Shape, Integration, 2B-PLS, CR Coefficient

\section{Introduction}

During life, fishes respond to predictable and unpredictable environmental dis- 
turbances; in juveniles the main motto is growth and survival and in adulthood mating and perpetuation of the species is primordial [1]. Pelagic larvaes settle on benthic habitats and this process optimizes their performance in essential activities like swimming, evading predators, feeding skills and defending territories, also involving changes converging with the gradual modification of their body shape [2]. In this sense, it is important to evaluate the morphological variations observed during growth and also to know which characteristics remain from larvae into adulthood [3].

The differences in size of a given organism are commonly associated with variation in its shape [4], where many traits are highly correlated [5]. The effect of size on fish biometrics has been a topic of discussion in traditional morphometrics (TM) and geometric morphometrics (GM). In TM, correction methods are used to eliminate the effect of size defining only the variables that can describe only the shape of the object, but this strategy is questionable due to the variability of results obtained [6]. In contrast, GM addresses comparisons between shapes during development focusing in the analyses of the Cartesian coordinates of the anatomical points that are of biological interest [4], and bases its methodology in the use of landmark coordinates (LM) that gather datasets of two or three coordinates. This method provides a robust tool to quantify the simple shape of a given geometric object without considering the effects of size, rotation, and translation, but conserving in this way information on the relative spatial locations of the data that allows the differentiation either at individual or at group level [7]. The variation in the allometric growth is not influenced by the analysis because there are no restrictions in the variability of changes in shape with these techniques [8]. GM analyses are very useful for the study of organisms that have completed morphogenesis, and that are at different growth stages, where the homologous characters are identified throughout all the life stages [2] [9]. The benefit of a quantitative description is the accuracy that provides the ability to recognize intermediate shapes, to judge degrees of proximity or similarity to other shapes and to extrapolate or predict possible shape extremes [9] [10].

Allometry provides information on growth regularities, evolution, and size changes required in shape for maintaining organism functionality in specific environments [11]. This variation could be generated by different biological phenomena including static allometry (intraspecific allometry) which reflects the individual variations within a single population and group of age; ontogenetic allometry that occurs due to development processes; and evolutionary allometry that reflects the covariation of different phylogenetic traits between taxa [12].

In organisms with modular organization, there are other levels of allometry which reflect morphological flexibility in response to the environment [5]. The phenotypic evolution studied trait by trait suggests that the body is composed of integrated units that are considered modular parts and are integrated into characters that are functionally related to evolutionary transformation units [13]. The modules consist of structural elements-or parts-that are to some extent morphologically and evolutionarily different or that develop over con- 
trasting times [14]. They maintain an internal relationship through multiple connections and interactions but remain relatively independent from each other in a way that the boundaries of each module can be recognizable [14] [15]. This pattern of strong internal connections and weaker external links is known as modularity that influences the patterns of morphological and evolutionary development.

In this sense, if the aim is to identify whether two or more structures are integrated through the ontogenic process, Partial Least Square (PLS) analysis provides an alternative to multivariate regression [4] [16]. This procedure is inferred from data obtained by the covariance analysis of multiple traits that have different degrees of emphasis due to the covariance strength, which is related to the variation between the dimensions of the morpho-space. The integration is stronger if all the variations are concentrated in one dimension, indicating a perfect correlation between all the measurements [15]; on the contrary, a fragile integration is when the connections between the different modules are scanty [16]. This process can be evaluated using two-block Partial Least Square analysis (2B-PLS), which consists of a set of external relationships ( $\mathrm{X}$ and $\mathrm{Y}$ as individual blocks) with an internal connection (linking the two blocks) [17]. The above are used in GM where one or both variables correspond to shapes, such as landmark coordinates of Procrustes aligned specimens or partial warp scores [18].

The red snapper Lutjanus campechanus (Poey, 1860) inhabits the continental platform in the Gulf of Mexico, from the Yucatan Peninsula and the southwestern of the Gulf of Mexico up to Key West in the Atlantic Coast [19]. Juvenile stages grow in shallow waters characterized by muddy and sandy landscapes, while adults live in rocky bottoms and reefs that provide shelter and food with a range of distribution in the water column from $10 \mathrm{~m}$ to $190 \mathrm{~m}$ depth [2] [3]. Maximum reported sizes range from 82 to $88 \mathrm{~cm}$ (in total length) and reproduction occurs over a period of nine months, with peaks in June to August, with a proportion of sexes (F:M) of 1.06:1.0 and size at maturity reported of $24.2 \mathrm{~cm}$ in males and $28.3 \mathrm{~cm}$ in females (total length) [20] [21]. In Mexico this species is under intense commercial and recreational fishing without effective regulation, despite being included in the IUCN Red List of threatened species with the category of Vulnerable (VU) [22].

The aim of this study was to evaluate the static ontogenetic growth of $L$. campechanus from early juvenile to adult stages using GM traits to establish morphological trends of the changes in trajectory and direction associated to shape occurring in these developmental stages to establish its integrative and/or modular nature, and to infer the ecological implications in each stage.

\section{Material and Methods}

\subsection{Study Area}

The Campeche Bank is located within the ecoregion of the Southern Gulf of Mexico and extends between $19^{\circ} 23^{\prime} \mathrm{N}$ and $89^{\circ} 93^{\prime} \mathrm{W}$ in the southern Gulf of Mex- 
ico. This region is the natural habitat of L. campechanus (Poey, 1860), being characterized by bottoms that have a bed suitable for the development of reef and rocky benthic communities, which are appropriate for the settlement of this species [23] (Figure 1).

\subsection{Sample Collection}

Between January and February of 2015 (northerly winds season), a total of 194 specimens with sizes ranging from 3 to $30 \mathrm{~cm}$ in standard length (SL) were purchased from commercial fleet that holds commercial permits and follows the guidelines established by the Mexican Regulations Fisheries NOM-002-PESC-2013 and by the National Fisheries Chart (DOF 15/03/04) and (SNFA/034/12). These permits are issued every two years by SAGARPA (Secretaria de Agricultura, Ganadería, Desarrollo Rural, Pesca y Alimentación) (https://www.inapesca.gob.mx/), based on their commercial catch. Juvenile red snappers were collected by shrimp trawls, whereas adults (larger than $20 \mathrm{~cm} \mathrm{SL}$ ) were collected with hand lines; organisms were purchased dead, maintained horizontally and kept in containers with ice until their arrival to the laboratory, where they were maintained at $-20^{\circ} \mathrm{C}$ for the subsequent analyses.

\subsection{Data Acquisition and Analysis}

The specimens were separated into 6 size classes: CL0: $3.0-4.9 \mathrm{~cm}$ (20 organisms), CL1: 5.0 - $9.9 \mathrm{~cm}$ (35 organisms), CL2: 10.0 - $14.9 \mathrm{~cm}$ (31 organisms) CL3: $15.0-19.9 \mathrm{~cm}$ (32 organisms), CL4: 20.0 - $24.9 \mathrm{~cm}$ (40 organisms) and CL5: 25.0 - $29.9 \mathrm{~cm}$ (35 organisms). The CL0, CL1, and CL2 classes corresponded to pre-recruits and early juveniles, while CL3, CL4, and CL5 classes included juveniles larger than $15 \mathrm{~cm}$, pre-adults and adults (individuals that had reached the size of their first sexual maturity) [21].

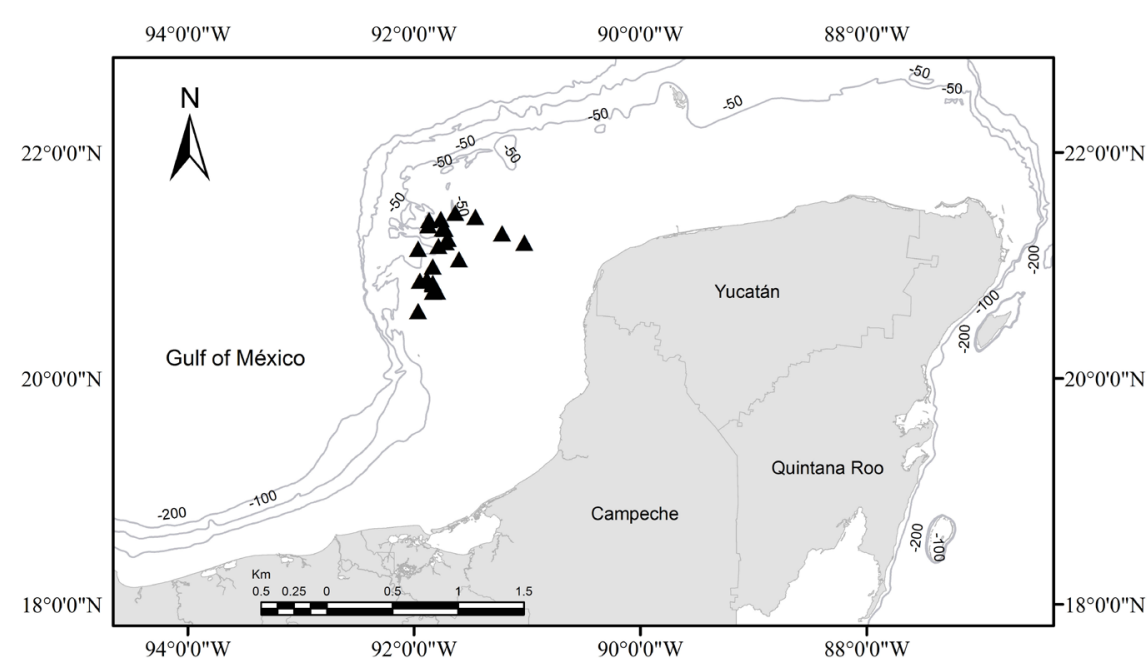

Figure 1. Sampling sites in the Campeche Bank, all locations are localized in the quadrant formed by $21^{\circ} 32^{\prime} 34.62^{\prime \prime} \mathrm{N}-92^{\circ} 03^{\prime} 48.22^{\prime \prime} \mathrm{W}$ and $20^{\circ} 30^{\prime} 29.52^{\prime \prime} \mathrm{N}-90^{\circ} 56^{\prime} 31.55^{\prime \prime} \mathrm{W}$ coordinates. 
Each specimen was photographed from its left side using a digital Olympus camera, with a resolution of 12.4 megapixels and macro option. The tripod was $50 \mathrm{~cm}$ distant from the baseboard and the camera was attached to a sliding arm to control the distance. The baseboard was covered with black plastic (ethylene vinyl acetate), to avoid the light reflexion and the presence of shadows.

The morphometric analyses were carried out based on a series of landmarks (LM) and sliding reference points (i.e. semi-landmarks: SLM), defined as the whole fish and the dorsal head profile (DHP) respectively. The selection of the appropriate LM was carried out based on the typology proposed by Bookstein [24], these correspond to types 1 and 2 and the SML to type 3. The final points consisted of 18 homologous points arranged along the fish's body (points 1 - 18), and 21 SML (points 19 - 39) along the curvature of the DHP (Figure 2(A) \& Figure 2(B)).

The program MakeFan6 was used to position the semi-landmarks SML equidistantly along the DHP [25]. Homologous landmark 1, 2 and three were used supporting points to draw a fan on the cranial region; these corresponded to the most distal point of the upper jaw, from the first spine of the dorsal fin up to the most distal point of the operculum. TPS files were generated using the software tpsUtil 1.58 [26]. Landmarks and SML were digitalized using the program tpsDig 2.16 [27]. Analysis of the LM data allowed the quantification of the changes in

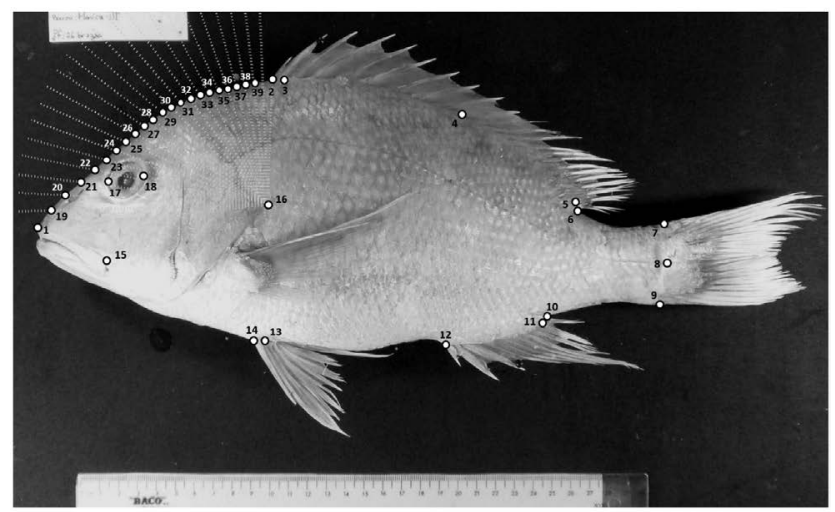

(A)

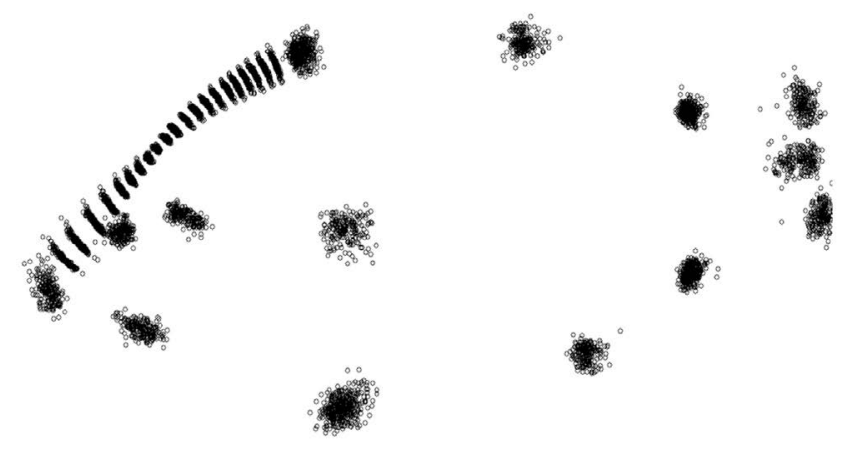

(B)

Figure 2. (A) The configuration of landmarks (LM: 1 - 18) and semilandmarks (SLM: marks 19 - 39); (B) Procrustes superimposition of 194 specimens. 
shape and direction throughout the development [8], for this, a non-parametric analysis and a morphometric-type exploratory analysis was performed.

The LM configurations were superimposed using the Generalized Procrustes Analysis (GPA) [28] [29]. The centroid and the effects due to the location, scale, and orientation of each of them were determined and removed using the Procrustes superimposition method of generalized least squares (GLS) [14]. These methods were used to record the LM configurations in a coordinate system that then is used as geometric variables [30]. The remaining differences in their location within the coordinate system were attributed to variation in shape. All data acquired were used as input data in the multivariate analysis.

The spline relaxation technique was also used to know if there was any change over the bowing on DHP at the same time of the development of the body: this procedure expands on the standard Procrustes superimposition method (GLS). The SML are slid along the curve of the profile until the positions of the corresponding points match as a reference configuration as closely as possible [31]. This analysis is called Relative Warp Analysis (RWA), and minimum Procrustes distance criterion was used. The Bookstein algorithm [24] was used, and then the points were slid along the tangent to the curve with 40 iterations. An alpha = 1 was used because the allometric effects tend to be large-scale [32]. After relaxation, the SLM were treated as if they were homologous reference points in the multivariate analysis [4].

After sliding, the Procrustes superimposition was recalculated to eliminate the information based on the original coordinates. This procedure was performed to standardize each specimen to a unit centroid size (CS: is a measure of geometric scale, defined as the square root of the sum of the squared distances of each reference point) [33]. The coordinates of all the aligned specimens were compared using the TPS function as a deformation method. In this way, the partial warps and their principal components or relative warps were calculated. The CS was obtained from this analysis, which represents a dispersion measure of LM around of the centroid. Further, a Principal Components Analysis (PCA) was performed on the weight matrix obtained from the RWA to examine the major trends of body shape variation.

Deformation grids were also obtained using a thin-plate spline analysis. This grid graphically described the variation between specimens by using the morphology of all the specimens to obtain an average shape where the position of the landmarks was compared, and the differences were represented as a deformed grid. Then changes in DHP shape were visualized to observe possible modifications in its curvature during fish development. These deformations were exaggerated three times to have a better perception of the morphological differences between classes. These analyses were performed in the tpsSpline 1.20 [34] and the tpsRelw 1.49 programs [35].

To evaluate the influence of size on shape, we performed a correlation analysis using the standard length against the CS (untransformed). The correlation value 
was $r^{2}=0.999(p<0.001)$, and the centroid was used as a proxy in all the subsequent analyses.

The differences between classes as a possible consequence of the change in the coordinates set during fish growth were evaluated by a one-way PERMANCOVA (999 permutations) performed over a Euclidean distance matrix (after log-transformation of the CS data). The partial warp scores generated for the Relative Warp Analysis were considered as variables, the logarithm of the centroid (LogCS) and SL were included as covariates and the classes as fixed factor. The CS is often used as a covariate in the morphometric analysis to consider the possible allometric effect of a size that is not explained by the scaling function of Procrustes superimposition [36]. This analysis was performed in the R package.

\subsection{Modularity and Integration Analysis}

The morphological integration between different regions of the body was evaluated using the "two-block Partial Least Square" (2B-PLS) analysis to establish the covariation of shape along the body among various modules. This procedure was performed using the tpsPLS program [37] creating pairs of variables, which are linear combinations of the original data of each block [18]. This test was also used to determine the combination of variables, in the two sets, that explained the highest covariation between them. The 2B-PLS analyses the variables of both modules symmetrically [i.e. it is not assumed that one set causes the other, that they are linearly related to one another, reflecting the responses of the underlying (unobserved) or latent variables] [4]. The correlation coefficient " $r$ " can be used as a measure of integration between the sets [15] [38]. The statistical validation for the 2B-PLS analyses was performed through a bootstrap test of 9999 permutations to determine whether the unique values produced were consistent with the null hypothesis of no significant covariance in the patterns between sets.

Modularity was evaluated using the CR coefficient (the covariance ratio) to verify the consistency of the results of the analysis of integration achieved by the singular warps analysis [39]. The CR coefficient is not affected by the sample size, or the number of variables (LM). Before the analyses, data were aligned using the Generalized Procrustes Analysis (GPA).Both indices range between 0 to 1 value, where 0 indicates the independence between modules and, therefore, the presence of modularity; and 1 implies a process of integrated development. 999 iterations were used to evaluate the level of significance during the procedure of permutations. Both analyses were performed in the R package Geomorph [40].

During growth, fish evolve hydrodynamic skills to guarantee survival at every stage of their life. They swim either using the body and the caudal fin, or a combination of the dorsal-anal fins and the pelvic-pectoral fins [41]. The body shape grows from a slender shape in the larval stage into a streamlined adult to provide very little resistance to the flow of water and to optimize its performance [42]. Based on these premises; the body of L. campechanus were partitioned in three modules: head (HD), trunk (TR), and tail (TL) to assess their modularity by 
growth and by class (Table 1). Each block landmarks were selected based on the same homology criteria; all points should be observed in the distinct stages of development to describe the transition from juveniles to reproductive adults.

\section{Results}

The PERMANCOVA analyses exhibited significant differences between classes $(p<0.001)$ showing that the LogCS covariate has a significant relationship with the morphometric coordinates $(\mathrm{p}<0.001)$. Although, the Classes-LogCS interaction was not significant (Table 2). The RWA values are described in Table 3. The first two elements provided the greatest information (95.93\%) on the morpho-space composition and reflected a deep contrast between the shapes of each class.

The LogCS had highly correlation with the standard length $(\mathrm{r}=0.969, \mathrm{p}<$ 0.01) (Figure 3(A) \& Figure 3(B)), (i.e. the shape is related to size, although the relationship is not purely linear). Conceptually, the CS is independent of shape, and it is only correlated when growth is allometric. For the variables LogCS and SL vs. RW1, the correlations were weak (Figure 3(B) \& Figure 3(C)). The correlations between RW2 and the variables Log CS and SL showed a moderate significant negative correlation with a large scatter of points. This could be

Table 1. Modules with specific landmarks and their individual description used in the Two-block Partial Least Square Analysis (DPH: dorsal head profile, LM: landmark).

\begin{tabular}{|c|c|c|}
\hline Module & LM & Location of homologous reference points \\
\hline \multirow{6}{*}{ Head } & 1 & Most distal point of the upper jaw \\
\hline & 2 & First spine of the dorsal fin \\
\hline & 14 & First spine of the pelvic fin \\
\hline & 15 & Commissureofmouth \\
\hline & $17-18$ & Eye \\
\hline & 16 & Most distal point of operculum \\
\hline \multirow{5}{*}{ Trunk } & $19-39$ & Semi-landmarks. DPH between LM 1 and 2 \\
\hline & 3 & Second spine of the dorsal fin \\
\hline & 4 & Last spine of the dorsal fin \\
\hline & 5 & Second last ray of the dorsal fin \\
\hline & 11 & Second last ray of the anal fin \\
\hline \multirow{7}{*}{ Tail } & 12 & First spine of the anal fin \\
\hline & 13 & Second spine of the pelvic fin \\
\hline & 6 & Last ray of the dorsal fin \\
\hline & 7 & Beginning of the caudal fin (dorsal view) \\
\hline & 9 & Beginning of the caudal fin (ventral view) \\
\hline & 10 & Last ray of anal fin \\
\hline & 8 & Final lateral line \\
\hline
\end{tabular}


Table 2. PERMANCOVA used over classes to categorize the developmental stages in red snapper (L. campechanus) (Poey, 1860). LogCS and SL were used as covariates. Significant results are shown in bold $(\mathrm{p}<0.001)$.

\begin{tabular}{cccccc}
\hline & Df & SS & MS & $F$ & P \\
\hline Classes & 1 & $9.0086 \mathrm{E}^{25}$ & $9.0086 \mathrm{E}^{25}$ & 29.7916 & 0.001 \\
LogCS & 10 & $1.8070 \mathrm{E}^{26}$ & $1.8070 \mathrm{E}^{26}$ & 5.9757 & 0.001 \\
SL & 1 & $2.9029 \mathrm{E}^{24}$ & $2.9029 \mathrm{E}^{24}$ & 0.9600 & 0.394 \\
Classes: LogCS & 4 & $9.7753 \mathrm{E}^{24}$ & $2.4438 \mathrm{E}^{24}$ & 0.8082 & 0.616 \\
Classes: SL & 1 & $1.1822 \mathrm{E}^{24}$ & $1.1822 \mathrm{E}^{24}$ & 0.3909 & 0.777 \\
Residuals & 176 & $5.3220 \mathrm{E}^{26}$ & $3.0239 \mathrm{E}^{24}$ & & \\
Total & 193 & $8.1684 \mathrm{E}^{26}$ & & & \\
\hline
\end{tabular}

Table 3. Principal component analysis (Relative warp analysis) (SA: singular axe; SV: unique value).

\begin{tabular}{cccc}
\hline SA & SV & \% Explainedvariance & \% Cumulativevariance \\
\hline 1 & $1.58 \mathrm{E} 24$ & 66.25 & 66.25 \\
2 & $7.09 \mathrm{E} 23$ & 29.68 & 95.95 \\
3 & $8.34 \mathrm{E} 22$ & 3.49 & 99.42 \\
\hline
\end{tabular}

because the RW2 axis expresses the contrast between the length and width of each specimen (Figure 3(D)-(F)). Although between RW1 and RW2 no correlation was observed (Figure 3(F)).

The distribution of the specimen scores along the first two components is shown in Figure 4(A). The Relative Warp 1 explained $66.25 \%$ of the variance; the primary variables of greatest value along this axis are in the DHP and corresponded to the SLM that described the change in the form as the body size increased showing an enhanced enlargement of the caudal peduncle. RW2 explained $29.68 \%$ of the variance, this axis described the augmentation of the height of the organisms according to their growth (LM 2 y 14); similarly, the variables of greatest value corresponded to the DHP (SLM plus the consistent element).

The results of the deformation grid for all the organisms showed that the regions of greatest variation were in the DHP and in the caudal region (Figure 4(A) \& Figure 4(B)). The projection of the displacement path of the LM on the upper half and the lower half of the DHP are in opposite directions and the LM of the caudal region are projected in the ventral direction, demonstrated by differences in the PC1 scores.

From the visual inspection of the deformation grids by class (Figure 4(A)), the main changes were observed in the head, and tail and they are more evident between classes 0,1 and $2 v s$. class 5, corresponding to recruits and early juveniles. The first two categories were characterized by large eyes close to the mouth that migrated to opposite positions in the largest class, while the profile becomes 

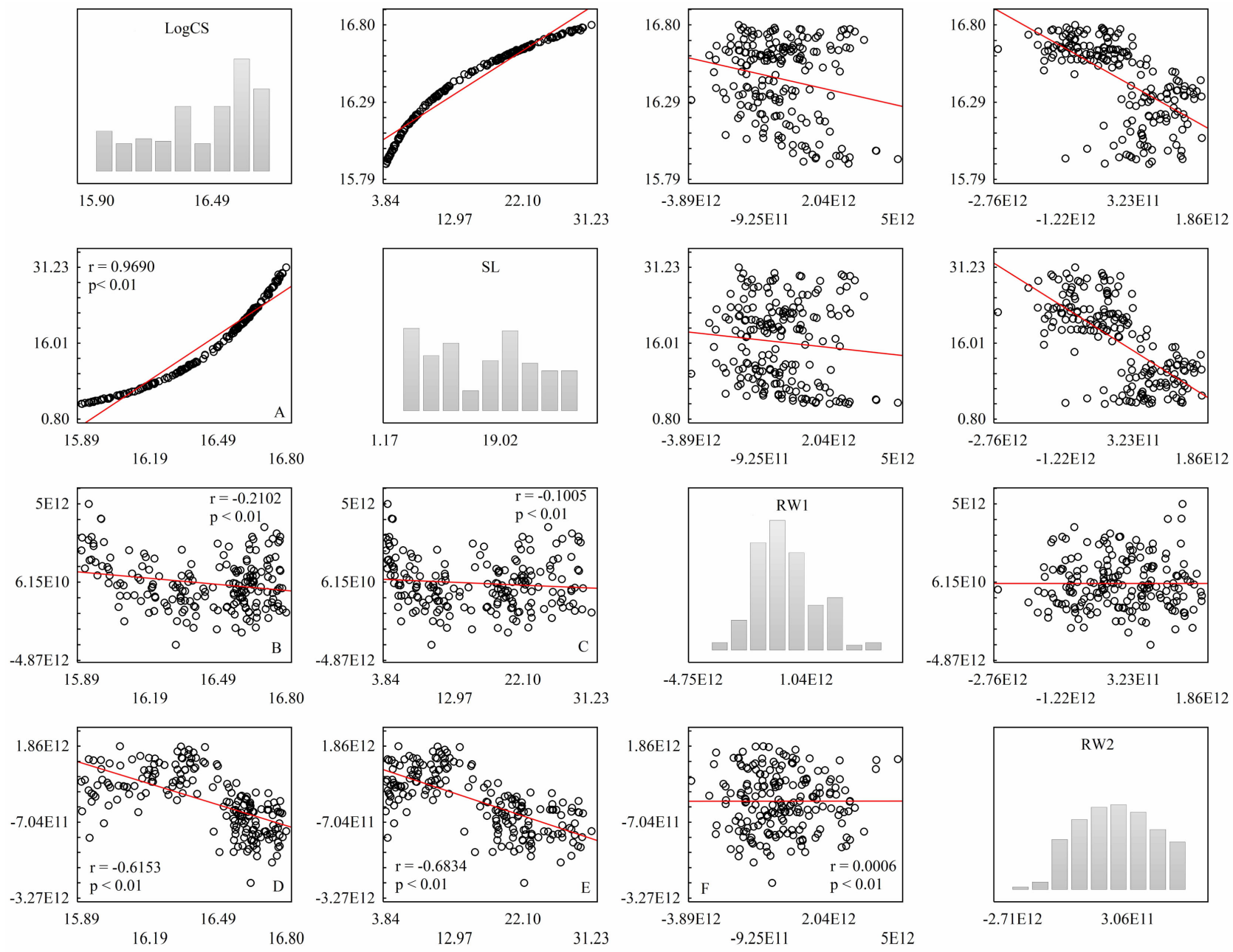

Figure 3. Matrix plot of correlations between the centroid logarithm (LogCS), standard length (SL) and relative warp axe (RW1 y RW2 scores). Regression values (r) and p-values are reported for each graphic. The frequency histogram represents the distribution of each variable.

more convex (Figure 4(A)). The gradual change in the direction of the mouth suggested an increase in the height of the rostrum. The trunk showed an increase almost proportional to the size of the head. The relationship between the trunk and tail (Table 5; $\mathrm{r}=0.621 ; \mathrm{p}<0.001$ ) is moderate, in the first classes the caudal peduncle is short and robust, getting longer and thinner towards the larger sizes. Visually constant changes are observed in the head and the tail, which seems more independent in comparison with changes compared to the other two modules, whereas the head and trunk are slightly more integrated regarding morphologic variations (Figure 4(A)).

Modularity and Morphological Integration: Shape analysis between blocks

The covariance between the pairs of modules analyzed was significant in all cases; the first singular value explained more than $90 \%$ of the total covariance for the HD-TL and TR-TL modules, and almost $75 \%$ for the HD-TR module (i.e. only one dimension shows significant covariance) (Table 4). 


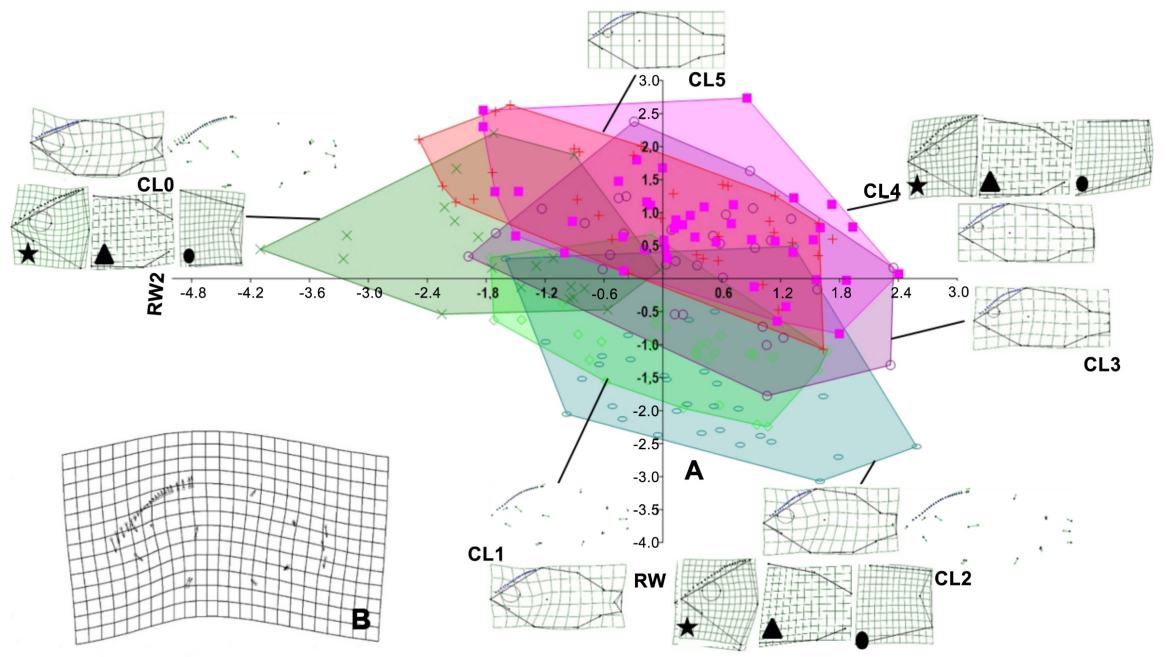

Figure 4. Consensus outline: (A) Relative Warp Analysis considering all landmarks (LM = 39) and all the samples (194 organisms). (B) Movement path of the landmarks (all specimens). CL0: Class 0 (X, $3-4.9 \mathrm{~cm}$, recruitments), CL1: Class $1(\diamond, 5-9.9 \mathrm{~cm}$, early juvenile), CL2: Class $2(\bigcirc, 10-14.9 \mathrm{~cm}$, juvenile), CL3: Class $3(\mathrm{O}, 15-19.9 \mathrm{~cm}$, juveniles > $15 \mathrm{~cm})$, CL4: Class $4(\square, 20-24.9 \mathrm{~cm}$, pre-adults), CL5: Class $5(+, 25-30 \mathrm{~cm}$, adult stage). HD: Head $*$, TR: Trunk, $\boldsymbol{\Delta}$, TL: Tail

Table 4. Total covariance explained by the first two singular axes and the covariance ratio for each module pair analyzed (CR coefficient).

\begin{tabular}{|c|c|c|c|c|c|c|}
\hline \multirow{2}{*}{ Module } & \multicolumn{4}{|c|}{ Two block PLS } & \multirow{2}{*}{ - CR coefficient } & \multirow{2}{*}{$\mathrm{p}$-value } \\
\hline & SA & Covariance & Percentage (\%) & $\%$ Cumulative & & \\
\hline \multirow[t]{2}{*}{ HD-TR } & 1 & $3.572988^{\mathrm{E}-004}$ & 75.64 & $75.64^{* *}$ & 1.5657 & 0.572 \\
\hline & 2 & $1.661885^{\mathrm{E}-004}$ & 16.36 & 92.00 & & \\
\hline \multirow[t]{2}{*}{ HD-TL } & 1 & $1.163037^{\mathrm{E}-003}$ & 94.22 & $94.22^{*}$ & 1.0761 & 0.454 \\
\hline & 2 & $2.310082^{\mathrm{E}-004}$ & 3.72 & 97.94 & & \\
\hline \multirow[t]{2}{*}{ TR-TL } & 1 & $8.460028^{\mathrm{E}-004}$ & 95.98 & $95.98^{*}$ & 1.114 & 0.618 \\
\hline & 2 & $1.212076^{\mathrm{E}-005}$ & 1.97 & 97.95 & & \\
\hline
\end{tabular}

$\left({ }^{*} \mathrm{p}<0.001 ;{ }^{* *} \mathrm{p}<0.05 ; \mathrm{n}=194\right)$. (SA: singular axes, HD: head, TR: trunk, TL: tail). ${ }^{*}{ }^{* *}$ statistical significant differences.

The highest correlation values were found between the HD-TR (0.684) and the HD-TL (0.663) with high significance (Table 5; $\mathrm{p}=0.001$ ). The highest correlations were observed in dimension 1 , and for the remaining dimensions the correlations were weak but significant. The values of correlations suggest that there is a moderate relationship between modules that increased slightly independent. The covariation between modules per class was almost equal for the two first axes in most of cases, although the cumulative percentage values for these axes only explain between $80 \%-88 \%$ of the variance.

The CL0 class showed the greatest covariance values between the HD-TL modules $(r=0.706$ on dimension 1 and $r=0.815$ on dimension 2$)$, but it was significant only for dimension $2(\mathrm{p}=0.005)$; the correlations between the other pairs of blocks for this class was moderate but not significant (Table 6). 
Table 5. Correlation analysis between the scores of the specimen's vectors along the singular axes of each pair of blocks by dimension (permutations: 9999 ; ${ }^{*} \mathrm{p}<0.001,{ }^{* *} \mathrm{p}=$ 0.0001; HD: head, TR: trunk, TL: tail; $\mathrm{n}=194$ ).

\begin{tabular}{ccc}
\hline Module & Dimension 1 & Dimension 2 \\
\hline HD-TR & $0.6836^{* *}$ & $0.4621^{* *}$ \\
HD-TL & $0.6628^{* *}$ & $0.2836^{*}$ \\
TR-TL & $0.6210^{* *}$ & $0.2479^{*}$ \\
\hline
\end{tabular}

*, ** statistical significant differences.

Table 6. Two-block Partial Least Square and the CR coefficient Analysis between module per class $(\mathrm{p}<0.001$; DIM = Dimention; CL0: Class 0, CL1: Class 1, CL2: Class 2, CL3: Class 3, CL4: Class 4, CL5: Class 5; HD: Head, TR: Trunk, TL: Tail).

\begin{tabular}{|c|c|c|c|c|c|c|}
\hline \multicolumn{7}{|c|}{ Two block Partial Least Square } \\
\hline Class & MD & DIM & $\mathrm{r}$ & p-value & CR coefficient & p-value \\
\hline \multirow[t]{2}{*}{ CLO } & HD-TR & 1 & 0.692915 & 0.233 & 1.0022 & 0.149 \\
\hline & & 2 & 0.670554 & 0.234 & & \\
\hline \multirow[t]{2}{*}{ CLO } & HD-TL & 1 & 0.705276 & 0.1945 & 1.045 & 0.212 \\
\hline & & 2 & 0.815714 & $0.0049^{*}$ & & \\
\hline \multirow[t]{3}{*}{ CLO } & TR-TL & 1 & 0.603293 & 0.577 & 1.1158 & 0.633 \\
\hline & & 2 & 0.583458 & 0.294 & & \\
\hline & HD-TR-TL & & & & 1.0479 & 0.189 \\
\hline \multirow[t]{2}{*}{ CL1 } & HD-TR & 1 & 0.648690 & $0.0306^{\star}$ & 1.0726 & 0.449 \\
\hline & & 2 & 0.674212 & $0.0047^{\star}$ & & \\
\hline \multirow[t]{2}{*}{ CL1 } & HD-TL & 1 & 0.638292 & $0.0283^{*}$ & 0.9447 & $0.019^{*}$ \\
\hline & & 2 & 0.502885 & 0.2481 & & \\
\hline \multirow[t]{3}{*}{ CL1 } & TR-TL & 1 & 0.492600 & 0.435 & 1.1143 & 0.688 \\
\hline & & 2 & 0.607666 & $0.016^{\star}$ & & \\
\hline & HD-TR-TL & & & & 0.9871 & $0.05900^{*}$ \\
\hline \multirow[t]{2}{*}{ CL2 } & HD-TR & 1 & 0.457796 & 0.808 & 1.0473 & 0.334 \\
\hline & & 2 & 0.493198 & 0.429 & & \\
\hline \multirow[t]{2}{*}{ CL2 } & HD-TL & 1 & 0.709059 & $0.003^{*}$ & 0.9286 & 0.00800 \\
\hline & & 2 & 0.503635 & 0.218 & & \\
\hline \multirow[t]{3}{*}{ CL2 } & TR-TL & 1 & 0.440186 & 0.587 & 1.0933 & 0.399 \\
\hline & & 2 & 0.460770 & 0.216 & & \\
\hline & HD-TR-TL & & & & 0.9984 & $0.047^{\star}$ \\
\hline \multirow[t]{2}{*}{ CL3 } & HD-TR & 1 & 0.556855 & 0.156 & 1.0615 & 0.387 \\
\hline & & 2 & 0.606045 & 0.023 & & \\
\hline \multirow[t]{2}{*}{ CL3 } & HD-TL & 1 & 0.553937 & 0.160 & 0.9888 & 0.031 \\
\hline & & 2 & 0.516882 & 0.053 & & \\
\hline CL3 & TR-TL & 1 & 0.493622 & 0.339 & 1.0897 & 0.455 \\
\hline
\end{tabular}




\begin{tabular}{|c|c|c|c|c|c|c|}
\hline \multicolumn{7}{|c|}{ Continued } \\
\hline & & 2 & 0.457373 & 0.251 & & \\
\hline & HD-TR-TL & & & & 0.9647 & $0.031^{\star}$ \\
\hline \multirow[t]{2}{*}{ CL4 } & HD-TR & 1 & 0.768343 & 0.0001 & 1.06 & 0.428 \\
\hline & & 2 & 0.443860 & 0.151 & & \\
\hline \multirow[t]{2}{*}{ CL4 } & HD-TL & 1 & 0.319136 & 0.981 & 1.0639 & 0.185 \\
\hline & & 2 & 0.316065 & 0.821 & & \\
\hline \multirow[t]{3}{*}{ CL4 } & TR-TL & 1 & 0.569432 & 0.124 & 1.0441 & 0.393 \\
\hline & & 2 & 0.381886 & 0.491 & & \\
\hline & HD-TR-TL & & & & 1.0454 & 0.083 \\
\hline \multirow[t]{2}{*}{ CL5 } & HD-TR & 1 & 0.523639 & 0.0789 & 1.0723 & 0.442 \\
\hline & & 2 & 0.535135 & $0.0418^{*}$ & & \\
\hline \multirow[t]{2}{*}{ CL5 } & HD-TL & 1 & 0.486377 & 0.1834 & 1.0579 & 0.164 \\
\hline & & 2 & 0.350178 & 0.628 & & \\
\hline \multirow[t]{3}{*}{ CL5 } & TR-TL & 1 & 0.541645 & 0.093 & 0.9859 & 0.252 \\
\hline & & 2 & 0.501468 & 0.084 & & \\
\hline & HD-TR-TL & & & & 1.0252 & 0.041 \\
\hline
\end{tabular}

*Statistical significant differences.

Class 1 exhibits a moderate significant correlation in HD-TR $(r=0.649$ on dimension 1 and $\mathrm{r}=0.674$ on dimension $2 ; \mathrm{p}<0.05$ ) and HD-TL blocks present a $r=0.638(p>0.05)$ in dimension 1; the blocks TR-TL show similar value but for dimension $2(r=0.608 ; p>0.05)$. The pre-recruits and recruits of classes 0,1 and 2 were characterized by oral structures that dominate in relation to the size of the head, in this block we found the most obvious sources of variation because the form of the head had a rising pattern from the oral opening and this marks tend to maximize the ability of the buccal opening. The structures of the mouth had morphological changes with growth related to eating habits and the way of obtaining prays from juveniles up to adulthood [43]. Another modification observed was in the eye area where the convex curvature of the eye increased from the longitudinal axis of the head.

Classes 2 and 3 showed similar $r$-values patterns in HD-TL blocks (dimension $1: \mathrm{p}<0.05$ ) and HD-TR (dimension 2: $\mathrm{p}<0.05$ ). Class 4 revealed a moderate correlation with a strong statistically significant value $(r=0.77, p=0.0001)$ in dimension 1and in the module HD-TR. Finally, Class 5 showed a weak to moderate correlation in HD-TR modules in dimension $2(\mathrm{r}=0.535, \mathrm{p}<0.05)$. There was a change in the cauda; it started from short and broad in recruit stage and changed into a slender and large in juvenile stage (CL1, 2 and 3). Meanwhile, the TR module did not show changes throughout the different classes, although statistically significant values are presented in the CL3 and CL4 involving a slight asynchrony in its growth, probably to compensate changes in the opercular area. 
The covariance pattern between blocks with all the specimens provided the highest resolution. All the patterns between sets for each class were characterized by more noticeable changes during early juvenile and juvenile stages and slower changes in stages that comprise the larger classes (Figure 4(A)). Despite this, the morphological changes in the blocks adjusted the relative positions of the landmarks as they increase in size remarking the high synchrony between the growth of the modules.

In the HD-TR covariance, the first two classes were probably associated to changes in the morpholpogy of the head and to a lesser extent to the displacement of the fins between both modules; whereas in the remaining classes, changes were only detected in the area of the nostrils and eyes because the shape of the head was more streamlined in the larger classes.

The results obtained with the CR coefficient, using the total number of copies by module (i.e., $\mathrm{n}=194$ ), did not show the same trends of statistical significance as the 2B-PLS analysis; according to this coefficient, $L$. campechanus had a highly integrated development process but it was not statistically significant (Table 4).

When the three modules were analyzed at the same time by class (HD-TR-TL), the values of $\mathrm{CR}=0.9$ were statistically significant $(\mathrm{p}<0.05)$ (Table 6). Although, with this analysis it was not possible to know which pair of modules contributed to this variation. The analysis of modules per pairs registered a slight independence between HD-TL, which is statistically significant for the classes 1,2 and $3(p<0.05)$. This trend was similar to that obtained in the 2B-PLS.

In CL5 the value of CR of the three modules suggested the same trend, but this was not detected in the analysis of modules by pairs, although the 2B-PLS logged a statistically significant correlation between the HD-TR modules of classes 3, 4 and 5 indicating that there is a moderate independence between both modules in larger classes. In this case the first two dimensions provided more information about the composition of the morpho-espace and reflected certain contrasts between forms of every kind. Once again, probably due to the change in eating habits of juveniles and adults.

\section{Discussion}

The ecomorphology approach studies the interaction between morphological and ecological diversity, to explain the morphological variations in individuals that result in functional differences and development [44]. In fishes, there is a clear relationship between shape and function allowing morphology to reflect adaptation to habitat and feeding niche [45]. Fishes comprise one of the most taxonomically diverse taxa, and their morphology varies intra specifically and inter specifically conditioned by different development pathways and functions, which depend on different behavior and lifestyles within a wide variety of ecosystems. Although the hydrodynamics of marine environments impose severe 
restrictions on their design, the presence of thousands of species living in different habitats demonstrates the existence of a wide variety of shapes. In that sense, some species can be classified according to a functional category about their shape (rover-predator $=$ fusiform, bottom fish $=$ flatfish, deep-body fish $=$ compressiform), and L. campechanus is categorized as compressiform associated to the structure of its habitat characterized by coral reefs [46].

Lutjanids, a group composed by 125 species, are generalist predators that belong to the rover-predator category with a downward mouth [19]. Typical snappers have a heavy and fusiform body with a dorsal fin, a sturdy and tight caudal peduncle and a slightly forked fin, and during the adult stage they have a triangular head with a large protractile mouth at the apex of the triangle, with fins distributed uniformly along the body, providing stability and maneuverability for their carnivorous habits [46].

\subsection{Shape Variation and Developmental Pattern}

The outcomes of this study represented a quantitative assessment of the shape of L. campechanus that provide more information on their morphometrics analysis. The sliding semi land-marks technique was used to explain changes in homologous anatomical loci with emphasis on the processes that modify the DHP curve during growth as a way of explaining the streamlined swimming ability that they experience during the distinct stages of their cycle.

During growth, the juveniles must achieve a high survival rate, and this process requires compensatory allometric changes in size so that functional abilities can be maintained until fish reach adult size [43]. The increase in fish size influences dramatically the performance in certain fundamental aspects of the interaction between the individual and the environment. Without these changes, the ability of adults to perform certain tasks, such as swimming, may be affected unless the initial performance levels are high enough to absorb reductions in their size-related skills [47]. In L. campechanus, the RWA showed a continuous distribution of specimens along the two principal axes. Samples that were either very positive or very negative along RW2 have a strong influence on the allocation of the values of the evaluated traits and revealed contrasts in shape related to the length and depth of the body for the size classes. The negative values along both axes corresponded to smaller size classes (CL0, CL1, and CL2), whereas the positive values corresponded to classes with an SL that exceeded $15 \mathrm{~cm}$. The specimens were equally distributed across the suggested size classes; hence the plot suggested that there was no clear size structuring in the populations from the catching site.

Lutjanidae family have both positive and negative allometric development [48] [49]. Mbaru et al. [48], Gómez et al. [50] and Manickchand-Heileman \& Phillip [51] reported almost isometric growth in $L$. bohar, $L$. vivanus, and $L$. purpureus respectively. In its early larval stage, L. campechanus (Poey, 1860) has an allometric growth pattern, regarding to length of trunk on the standard 
length [52], allowing a faster development of the structures needed for feeding and locomotion [53] [54]. This could explain that the head showed great variations in the LM trajectories and tail of the smallest SL size classes (CLO, CL1, and CL2). In these groups, they are still growing, and their main functions are feeding and avoiding predation. The deformation grid of the thin plate analysis for each size class showed that the first three size classes had the most compelling changes in the head and caudal peduncle. It has been estimated that in larvae, the head can comprise up to $45 \%$ of the body length [55], a proportion that progressively decreases with growth.

All the variations experienced by $L$. campechanus (Poey, 1860) reflected a growth pattern like that found in the common carp [53]. These differential trends determine the size-shape relationship during ontogeny. When shape and size are linked by an allometric-type relationship, a change in size corresponds linearly to a change in shape [5]. An in theory, sizes larger than $50 \mathrm{~cm}$ SL of growth becomes almost isometric [56].

\subsection{Hydrodynamics}

Some fish use distinct parts of the body during swimming related activities like predator evasion, prey capture and navigation in structurally complex environments [57]. The hydrodynamics of the environment influence partially the shape of fishes; for example, macro carnivores have kept fusiform shapes enabling them to have less friction with the water to have a greater and faster displacement, and the environment that fishes face depends on the individual size, the speed at which it moves, and the physical properties of the water itself (viscosity and density) [58] [59]. During ontogeny, fishes regime changes on the environment, because they get bigger and faster, and the relationship between inertia and viscosity change as they develop, altering their swimming behavior [42] [58] [59], which will affect the ability to escape predators [60].

The types of forces acting on a moving fish differ according to the hydrodynamic regime. The Reynolds number is used as an index to identify the hydrodynamic regimes experienced by the fish: $\mathrm{Re}=\mathrm{UL} / \mathrm{v}$, where $\mathrm{U}$ and $\mathrm{L}$ are the velocity and length of the fish and $\mathrm{v}$ are the kinematic viscosity of the water [61]. The regime of inertial forces dominates when Re $>200$ (inertial regime), however, viscous forces prevail when $\mathrm{Re}>1$ (viscous regime) and are significant for larvae up to $\mathrm{Re}=30$. At $30<\mathrm{Re}<200$ an intermediate zone is estimated, in which the balance between the two forces is gradually displaced from a viscous liquid to an inertial regime. Borazjani \& Sotiropoulos [62] found that at low $R e$ the larvae present greater fluctuations in swimming speed than adult fish; their results demonstrate that all fish swam more efficiently if they had a body shape or swimming style suitable to the speeds at which they swam. The fish swimming speed leads to rates of hydrodynamic forces that will influence the body shape and swimming style in subsequent stages favoring the balance between swimming bursts, needed for a rapid response to predation events during 
the youngest stage and the swimming sustained. These features are essential for activities such as foraging or searching for a mate in adult stages [36] [63] [64] [65].

In early stages (early juveniles and juveniles), L. campechanus (Poey, 1860) specimens had arge heads ending in a slightly pointed forehead and more sleek bodies when compared to adult shapes [21] [58]. This could explain the displacement paths observed in the thin plate analysis because the allometric growth influence over the variables of shape was detected with the PERMANCOVA analysis. In this case, the LogCS covariate explained a high percentage of variance on the effect of increase between classes. These changes in shape occurred mainly in the profile of the face and the structures of the head, in which the SLM undergo necessary changes in position on the anterior and dorsoventral axes of the body. The changes in shape reflected the transition from early juvenile to adult involving these regions, confirming the general findings reported in the RWA.

\subsection{Modularity}

Modularity is the partitioning of the integration into evolutionarily or developmentally independent blocks of traits. Sizes and shapes of the body (or their parts) vary in a coordinated manner as a whole functional group [15]. This process is measured by statistical associations between traits [66]. The structure of these associations reflects the processes that affect certain traits but not others. These are covariance-generating processes that influence the patterns of morphological integration [67] that can be modified by mutations, by development dynamics or by environmental processes.

The study of ontogenetic morphological development in fish was based on the study of allometric models of three different regions detected along the anterior caudal axis: head, trunk, and tail [2] [53] [68]. According to our results and the configuration proposed herein, L. campechanus (Poey, 1860) has a modular conformation during growth. The greatest covariance between the modules was explained by SA1, although there were no significant differences between values, there were slight differences in growth outlines along the anteroposterior axis. The correlation value between the head and the trunk indicated that these modules maintained a slight synchrony in the development process; a large head corresponding to a deep trunk and this proportion is clearer in larger sizes.

In this study, a certain pattern of morphological integration between the head and trunk was observed, although this relationship was not strictly linear. The development of the tail was modular and independent from the other blocks. The head and the tail developed before the trunk of the body, and increases in depth quite late in development, this because of a possible adaptation to reduce transporting costs [54].

Genetic or environmental factors could also affect development of larvae but may have minor impact on trunk depth. Therefore, if development time explains 
integration, we could anticipate a greater correlation between parts that develop at the same time [4]. According to Klingenberg [16], the skull is designed to overcome mechanical forces produced during chewing, capture and processing of prey, respiration, and vocalization. In this sense, Osse et al. [53] demonstrated that during initial stages, feeding is a vital process that governs the speed of growth (positive allometric) of the head and all related structures.

The morphological development of larvae seems to be a process in which modularity and integration are two basic strategies [69]. The rate of development could contribute to the ontogenetic patterns detected by variance and integration; i.e. a high variance and low integration would be expected in smaller size classes, and a decrease in variance and increase in integration would be expected in mature individuals [67]. Pressure, friction, and resistance to movement are factors that highly depend on shape, because of isometric scaling and increase in mass. Acceleration during bursts and fast-starts may decrease due to an increase in size [70] [71]. However, Gibb et al. [59] found that escape performance improved with the development of adult morphology; hence, fish that enter the environment in an advanced development phase should have a greater ability to evade predators than those that enter during an early stage of development. Antonucci et al. [72] concluded that in adults the shape of apex predators is similar to the "BCF-transient" type proposed by Webb [73] since they can display a fast start, powerful turns, and powerful propulsion. Propulsion is provided by a long and narrow caudal peduncle. Evolution of uncoupled locomotive systems was an important factor underlying the adaptive radiation of teleosts [74].

The relative importance of the caudal module depth can depend on the context of the predator-prey interaction. The lutjanids are an opportunistic species that belongs to the mid- and top predator category focusing on slow-moving prey (crabs, shrimp \& small fish). Adults L. campechanus (Poey, 1860) have few predators and their body are elevated depth, narrow caudal peduncle and small eyes [72]. The adult organisms are associated with depressions and high relief structures such as reefs and rocks [21]. During developmental stage, they do not move far from their settlement site [75]. This type of predatory behavior and lifestyle are the reason behind a body shape that is better adapted to sustained and prolonged swimming during its adult stage.

Finally, the size range used in this study was limited to the scale of the first sexual maturity, which is why the effects of variation between the last two classes were not observed. Morphological design for each stage of development reflects a correspondence where performance is optimized according to environmental conditions where they inhabit. In juveniles living in soft bottoms or low shallow areas of open water $(<24 \mathrm{~m})$, with moderate to strong currents, the structural complexity is minimal. Its fusiform shape could confer them certain ecological advantages, such as stability in swimming and fast-start performance that would increase their rate of survival in fast moving waters and high exposure to predators. The largest classes live associated with rocks or coral reefs in environments 
that are steadier; its body shape is deeper and robust designed for sustained swimming necessary for the switch to a more sedentary lifestyle. In future studies, it would be desirable to supplement this information including larger specimens (i.e. above $50 \mathrm{~cm} \mathrm{SL}$ ), a size at which this species continues to grow only isometrically [56].

\section{Conclusion}

This is the first ecomorphological report of L. campechanus in Mexico with the aim to identify patterns among morphology, behavioral performance and ecology. This study described the development patterns during ontogenetic growth and change in shape in L. campechanus (Poey, 1860) using geometric morphometric techniques. The trend observed during early and young juvenile stages were slightly more streamlined than during adulthood, i.e. the modular development processes during growth optimized certain structures of the body (head, body, tail). The development of the head and tail was a fast process occurring between lengths of 3 and $15 \mathrm{~cm}$ SL (CL0-CL2), being the head, the module that experienced significant variations in lengths up to $20 \mathrm{~cm} \mathrm{SL}$.

\section{Acknowledgements}

Special thanks are conveyed to the shrimp fleet owners and to Mr. Cesar M. Ceballos from Conservas de Campeche S.A. de C.V. S. for helping with the collection of fishes, to Mrs. Mirella Hernández and to Mr. Alex Acosta, for their technical support in the laboratory. EM holds a PhD scholarship (No. 324812) from CONACyT, Mexico. The Globalzone Science \& High Technology A.C. and internal budgets of the laboratories of Nekton and Immunology from CINVESTAV IPN Unidad Merida supported this work.

\section{Conflicts of Interest}

The authors declare no conflicts of interest regarding the publication of this paper.

\section{References}

[1] Walker, J.A. (2010) An Integrative Model of Evolutionary Covariance: A Symposium on Body Shape in Fishes. Integrative and Comparative Biology, 50, 1051-1056. https://doi.org/10.1093/icb/icq014

[2] Loy, A., Mariani, L., Bertelletti, M. and Tunesi, L. (1998) Visualizing Allometry: Geometric Morphometrics in the Study of Shape Changes in the Early Stages of the Two-Banded Sea Bream, Diplodus vulgaris (Perciformes, Sparidae). Journal of Morphology, 237, 137-146. https://doi.org/10.1002/(SICI)1097-4687(199808)237:2<137::AID-JMOR5>3.0.CO;2 $\underline{-Z}$

[3] Slice, D.E. (2007) Geometric Morphometrics. Annual Review of Anthropology, 36, 261-281. https://doi.org/10.1146/annurev.anthro.34.081804.120613

[4] Zelditch, M.L., Swiderski, D.L., Sheets, H.D. and Fink, W.L. (2004) Geometric Morphometrics for Biologists. 2nd Edition, Elsevier Academic Press, New York, USA. 
[5] Klingenberg, C.P. (1996) Multivariate Allometry. In: Marcus, L., Corti, M., Loy, A., Naylor, G.P. and Slice, D., Eds., Advances in Morphometrics, Springer, US, 23-49. https://doi.org/10.1007/978-1-4757-9083-2_3

[6] Toro-Ibacache, M.V., Soto, G.M. and Galdames, I.S. (2010) Morfometría geométrica y el estudio de las formas biológicas: De la morfología descriptiva a la morfología cuantitativa. International Journal of Morphology, 28, 977-990. https://doi.org/10.4067/S0717-95022010000400001

[7] Kendall, D.G. (1977) The Diffusion of Shape. Advances in Applied Probability, 9, 428-430. https://doi.org/10.2307/1426091

[8] Viscosi, V. and Cardini, A. (2011) Leaf Morphology, Taxonomy and Geometric Morphometrics: A Simplified Protocol for Beginners. PLoS ONE, 6, e25630. https://doi.org/10.1371/journal.pone.0025630

[9] Roth, V.L. and Mercer, J.M. (2000) Morphometrics in Development and Evolution. Integrative and Comparative Biology, 40, 801-810. https://doi.org/10.1093/icb/40.5.801

[10] Larson, P.M. (2005) Ontogeny, Phylogeny, and Morphology in Anuran Larvae: Morphometric Analysis of Cranial Development and Evolution in Rana Tadpoles (Anura: Ranidae). Journal of Morphology, 264, 34-52. https://doi.org/10.1002/jmor.10313

[11] Gayon, J. (2000) History of the Concept of Allometry. Integrative and Comparative Biology, 40, 748-758. https://doi.org/10.1093/icb/40.5.748

[12] Cheverud, J.M. (1970) Relationships among Ontogenetic, Static, and Evolutionary Allometry. American Journal of Physical Anthropology, 59, 139-149. https://doi.org/10.1002/ajpa.1330590204

[13] Wagner, G.P. (1996) Homologues, Natural Kinds and the Evolution of Modularity. Integrative and Comparative Biology, 36, 36-43. https://doi.org/10.1093/icb/36.1.36

[14] Klingenberg, C.P. (2002) Morphometrics and the Role of the Phenotype in Studies of the Evolution of Developmental Mechanisms. Gene, 287, 3-10. https://doi.org/10.1016/S0378-1119(01)00867-8

[15] Klingenberg, C.P., Badyaev, A.V., Sowry, S.M. and Beckwith, N.J. (2001) Inferring Developmental Modularity from Morphological Integration: Analysis of Individual Variation and Asymmetry in Bumblebee Wings. The American Naturalist, 157, 11-23. https://doi.org/10.1086/317002

[16] Klingenberg, C.P. (2008) Morphological Integration and Developmental Modularity. Annual Review of Ecology, Evolution, and Systematics, 39, 115-132. https://doi.org/10.1146/annurev.ecolsys.37.091305.110054

[17] Geladi, P. and Kowalski, B.R. (1986) Partial Least-Squares Regression: A Tutorial. Analytica Chimica Acta, 185, 1-17. https://doi.org/10.1016/0003-2670(86)80028-9

[18] Rohlf, F.J. and Corti, M. (2000) Use of Two-Block Partial Least-Squares to Study Covariation in Shape. Systematic Biology, 49, 740-753. https://doi.org/10.1080/106351500750049806

[19] Allen, G.R. (1985) FAO Species Catalogue, vol. 6. Snappers of the World: An Annotated and Illustrated Catalogue of Lutjanidae Species Known to Date. FAO Fisheries Synopsis No. 125, 208.

[20] McEachran, J.D. and Felhhelm, J.D. (1998) Fishes of the Gulf of Mexico. Volume 1, University of Texas Press, Austin, Texas, $112 \mathrm{p}$.

[21] Brulé, T., Colás-Marrufo, T., Pérez-Díaz, E. and Sámano-Zapata, J.C. (2010) Red Snapper Reproductive Biology in the Southern Gulf of Mexico. Transactions of the 
American Fisheries Society, 139, 957-968. https://doi.org/10.1577/T09-125.1

[22] Anderson, W., Claro, R., Cowan, J., Lindeman, K., Padovani-Ferreira, B. and Rocha, L.A. (2015) Lutjanus campechanus. IUCN Red List Threat Species 2015, e.T194365A115334224.

[23] Lara-Lara, J., Arenas-Fuentes, V., Bazán-Guzmán, C., Díaz-Castañeda, V., EscobarBriones, E., García-Abad, M.C., Gaxiola-Castro, G., Robles-Jarero, G., Sosa-Ávalos, R. and Soto-González, L. (2008) Los ecosistemas marinos. Capital natural de México, 135-159.

[24] Bookstein, F.L. (1991) Morphometric Tools for Landmark Data Geometry and Biology. Cambridge University Press, London.

[25] Shetts, H. (2003) IMP-Integrated Morphometrics Package. Department of Physics, Canisius College, Buffalo. https://www3.canisius.edu/ sheets/morphsoft

[26] Rohlf, F.J. (2010) tpsUtil File Utility Program. Version 1.58. Department of Ecology and Evolution, State University of New York, Stony Brook. http://life.bio.sunysb.edu/morph/

[27] Rohlf, F.J. (2010) tpsDig File Utility Program. Version 2.16. Department of Ecology and Evolution, State University of New York, Stony Brook. http://life.bio.sunysb.edu/morph/

[28] Goodall, C. (1991) Procrustes Methods in the Statistical Analysis of Shape. Journal of the Royal Statistical Society: Series B, 53, 285-339.

[29] Rohlf, F.J. (1999) Shape Statistics: Procrustes Superimpositions and Tangent Spaces. Journal of Classification, 16, 197-223. https://doi.org/10.1007/s003579900054

[30] Slice, D.E. (2005) Modern Morphometrics in Physical Anthropology. Kluwer Academic/Plenum Publishers, New York. https://doi.org/10.1007/0-387-27614-9

[31] Adams, D.C., Rohlf, F.J. and Slice, D.E. (2004) Geometric Morphometrics: Ten Years of Progress Following the "Revolution". Italian Journal of Zoology, 71, 5-16. https://doi.org/10.1080/11250000409356545

[32] Rohlf, F.J. (1993) Relative Warp Analysis and an Example of Its Applications to Mosquito Wings. In: Marcus, L., Bello, E. and García-Valdecasas, A., Eds., Contributions to Morphometrics, Museo Nacional de Ciencias Naturales, Madrid, 131-159.

[33] Dryden, I.L. and Mardia, K.V. (1998) Statistical Shape Analysis. John Wiley \& Sons, Chichester.

[34] Rohlf, F.J. (2004) tpsSpline File Utility Program. Version 1.20. Department of Ecology and Evolution, State University of New York, Stony Brook. http://life.bio.sunysb.edu/morph/

[35] Rohlf, F.J. (2010) tpsRelw File Utility Program. Version 1.49. Department of Ecology and Evolution, State University of New York, Stony Brook. http://life.bio.sunysb.edu/morph/

[36] Hassell, E.M.A., Meyers, P.J., Billman, E.J., Rasmussen, J.E. and Belk, M.C. (2012) Ontogeny and Sex Alter the Effect of Predation on Body Shape in a Livebearing Fish: Sexual Dimorphism, Parallelism, and Costs of Reproduction. Ecology and Evolution, 2, 1738-1746. https://doi.org/10.1002/ece3.278

[37] Rohlf, F.J. (2014) tpsPLS File Utility Program. Version 1.21. Department of Ecology and Evolution, State University of New York, Stony Brook. http://life.bio.sunysb.edu/morph/

[38] Bookstein, F.L., Gunz, P., Mitteroecker, P., Prossinger, H., Schaefer, K. and Seidler, H. (2003) Cranial Integration in Homo: Singular Warps Analysis of the Midsagittal 
Plane in Ontogeny and Evolution. Journal of Human Evolution, 44, 167-187. https://doi.org/10.1016/S0047-2484(02)00201-4

[39] Adams, D.C. (2016) Evaluating Modularity in Morphometric Data: Challenges with the RV Coefficient and a New Test Measure. Methods in Ecology and Evolution, 7, 565-572. https://doi.org/10.1111/2041-210X.12511

[40] Adams, D.C., Collyer, M.L., Kaliontzopoulou, A. and Sherratt, E. (2017) Geomorph: Software for Geometric Morphometric Analyses. R Package Version 3.0.5. https://cran.r-project.org/package=geomorph

[41] Sfakiotakis, M., Lane, D.M. and Davies, J.B.C. (1999) Review of Fish Swimming Modes for Aquatic Locomotion. IEEE Journal of Oceanic Engineering, 24, 237-252. https://doi.org/10.1109/48.757275

[42] McHenry, M.J. and Lauder, G.V. (2006) Ontogeny of Form and Function: Locomotor Morphology and Drag in Zebrafish (Danio rerio). Journal of Morphology, 267, 1099-1109. https://doi.org/10.1002/jmor.10462

[43] Case, J.E., Westneat, M.W. and Marshall, C.D. (2008) Feeding Biomechanics of Juvenile Red Snapper (Lutjanus campechanus) from the Northwestern Gulf of Mexico. Journal of Experimental Biology, 211, 3826-3835.

https://doi.org/10.1242/jeb.014464

[44] Betz, O. (2006) Ecomorphology: Integration of Form, Function, and Ecology in the Analysis of Morphological Structures. Mitteilungen der Deutschen Gesellschaft für Allgemeine und Angewandte Entomologie, 15, 409-416.

[45] Robinson, B.W. and Wilson, D.S. (1996) Genetic Variation and Phenotypic Plasticity in a Trophically Polymorphic Population of Pumpkinseed Sunfish (Lepomis gibbosus). Evolutionary Ecology, 10, 631-652. https://doi.org/10.1007/BF01237711

[46] Moyle, P.B. and Cech, J.J. (2004) Fishes: An Introduction to Ichthyology. 5th Edition, Prentice-Hall, Upper Saddle River.

[47] Maie, T., Schoenfuss, H.L. and Blob, R.W. (2012) Performance and Scaling of a Novel Locomotor Structure: Adhesive Capacity of Climbing Gobiid Fishes. Journal of Experimental Biology, 215, 3925-3936. https://doi.org/10.1242/jeb.072967

[48] Mbaru, E.K., Mlewa, C.M. and Kimani, E.N. (2010) Length-Weight Relationship of 39 Selected Reef Fishes in the Kenyan Coastal Artisanal Fishery. Fisheries Research, 106, 567-569. https://doi.org/10.1016/j.fishres.2010.09.012

[49] Nieto-Navarro, J., Zetina-Rejón, M., Arreguín-Sánchez, F., Arcos-Huitrón, N. and Peña-Messina, E. (2010) Length-Weight Relationship of Demersal Fish from the Eastern Coast of the Mouth of the Gulf of California. Journal of Fisheries and Aquatic Science, 5, 494-502. https://doi.org/10.3923/jfas.2010.494.502

[50] Gómez, G., Guzmán, R. and Marcano, L. (1996) Biological Aspects of the Yellow Eye Snapper (Lutjanusvivanus) (Pisces: Lutjanidae) from Los Hermanos Islands, Eastern Venezuela. In: Arreguín-Sanchez, F., Munro, J., Balgos, M. and Pauly, D., Eds., Biology, Fisheries and Culture of Tropical Groupers and Snappers, ICLARM, 51-58.

[51] Manickchand-Heileman, S. and Phillip, D. (1996) Reproduction, Age and Growth of the Caribbean Red Snapper (Lutjanuspurpureus) in Waters of Trinidad and Tobago. In: Arreguín-Sanchez, F., Munro, J., Balgos, M. and Pauly, D., Eds., Biology, Fisheries and Culture of Tropical Groupers and Snappers, ICLARM, 137-149.

[52] Williams, K., Papanikos, N., Phelps, R.P. and Shardo, J.D. (2004) Development, Growth, and Yolk Utilization of Hatchery-Reared Red Snapper Lutjanus campechanus Larvae. Marine Ecology Progress Series, 275, 231-239. 
https://doi.org/10.3354/meps275231

[53] Osse, J.W., Sibbing, F.A. and van den Boogaart, J.G. (1997) Intra-Oral Food Manipulation of Carp and Other Cyprinids: Adaptations and Limitations. Acta Physiologica Scandinavica. Supplementum, 638, 47-57.

[54] Gisbert, E., Merino, G., Muguet, J., Bush, D., Piedrahita, R. and Conklin, D. (2002) Morphological Development and Allometric Growth Patterns in Hatchery-Reared California Halibut Larvae. Journal of Fish Biology, 61, 1217-1229. https://doi.org/10.1111/j.1095-8649.2002.tb02466.x

[55] Drass, D.M., Bootes, K.L., Lyczkowski-Shultz, J., Comyns, B.H., Holt, G.J., Riley, C.M. and Phelps, R.P. (2000) Larval Development of Red Snapper, Lutjanus campechanus, and Comparisons with Co-Occurring Snapper Specie. Fishery Bulletin, 98, 507-527.

[56] Nelson, R.S. and Manooch, C.S. (1982) Growth and Mortality of Red Snappers in the West-Central Atlantic Ocean and Northern Gulf of Mexico. Transactions of the American Fisheries Society, 111, 465-475. https://doi.org/10.1577/1548-8659(1982)111<465:GAMORS>2.0.CO;2

[57] Langerhans, R.B. and Reznick, D. (2010) Ecology and Evolution of Swimming Performance in Fishes: Predicting Evolution with Biomechanics. In: Domenici, P. and Kapoor, B., Eds., Fish Locomotion an Etho-Ecological Perspect, Science Publishers, Enfield, 200-248. https://doi.org/10.1201/b10190-8

[58] Patterson, William, F., Wilson, C.A. and Shipp, R.L. (2001) Age and Growth of Red Snapper, Lutjanus campechanus, from an Artificial Reef Area off Alabama in the Northern Gulf of Mexico. Fishery Bulletin, 99, 617.

[59] Gibb, A.C., Swanson, B.O., Wesp, H., Landels, C. and Iu, C. (2006) Development of the Escape Response in Teleost Fishes: Do Ontogenetic Changes Enable Improved Performance? Physiological and Biochemical Zoology, 1, 7-19. https://doi.org/10.1086/498192

[60] Hale, M.E. (1996) The Development of Fast-Start Performance in Fishes: Escape Kinematics of the Chinook Salmon (Oncorhynchus tshawytscha). American Zoologist, 36, 695-709. https://doi.org/10.1093/icb/36.6.695

[61] Fuiman, L.A. and Webb, P.W. (1988) Ontogeny of Routine Swimming Activity and Performance in Zebra Danios (Teleostei: Cyprinidae). Animal Behaviour, 36, 250-261. https://doi.org/10.1016/S0003-3472(88)80268-9

[62] Borazjani, I. and Sotiropoulos, F. (2010) On the Role of Form and Kinematics on the Hydrodynamics of Self-Propelled Body/Caudal Fin Swimming. Journal of Experimental Biology, 213, 89-107. https://doi.org/10.1242/jeb.030932

[63] Langerhans, R.B., Layman, C.A., Shokrollahi, A.M. and DeWitt, T.J. (2004) Predator-Driven Phenotypic Diversification in Gambusia affinis. Evolution, 58, 2305-2318. https://doi.org/10.1111/j.0014-3820.2004.tb01605.x

[64] Langerhans, R.B. (2009) Morphology, Performance, Fitness: Functional Insight into a Post-Pleistocene Radiation of Mosquitofish. Biology Letters, 5, 488-491. https://doi.org/10.1098/rsbl.2009.0179

[65] Baliga, V.B. and Mehta, R.S. (2016) Ontogenetic Allometry in Shape and Flexibility Underlies Life History Patterns of Labrid Cleaning Behavior. Integrative and Comparative Biology, 56, 416-427. https://doi.org/10.1093/icb/icw028

[66] Cheverud, J.M. (1982) Phenotypic, Genetic and Environmental Integration in the Cranium. Evolution, 36, 499-512.

https://doi.org/10.1111/j.1558-5646.1982.tb05070.x 
[67] Fischer-Rousseau, L., Cloutier, R. and Zelditch, M.L. (2009) Morphological Integration and Developmental Progress during Fish Ontogeny in Two Contrasting Habitats. Evolution \& Development, 11, 740-753.

https://doi.org/10.1111/j.1525-142X.2009.00381.x

[68] Klingenberg, C.P., Barluenga, M. and Meyer, A. (2003) Body Shape Variation in Cichlid Fishes of the Amphilophus citrinellus Species Complex. Biological Journal of the Linnean Society, 80, 397-408. https://doi.org/10.1046/j.1095-8312.2003.00246.x

[69] Fuiman, L.A. (1983) Growth Gradients in Fish Larvae. Journal of Fish Biology, 23, 117-123. https://doi.org/10.1111/j.1095-8649.1983.tb02886.x

[70] Walker, J.A. (1997) Ecological Morphology of Lacustrine Threespine Stickleback Gasterosteus aculeatus L. (Gasterosteidae) Body Shape. Biological Journal of the Linnean Society, 61, 3-50.

[71] Domenici, P. (2001) The Scaling of Locomotor Performance in Predator-Prey Encounters: From Fish to Killer Whales. Comparative Biochemistry and Physiology Part A: Molecular \& Integrative Physiology, 131, 169-182. https://doi.org/10.1016/S1095-6433(01)00465-2

[72] Antonucci, F., Costa, C., Aguzzi, J. and Cataudella, S. (2009) Ecomorphology of Morpho-Functional Relationships in the Family of Sparidae: A Quantitative Statistic Approach. Journal of Morphology, 270, 843-855. https://doi.org/10.1002/jmor.10725

[73] Webb, P.W. (1984) Body Form, Locomotion and Foraging in Aquatic Vertebrates. American Zoologist, 24, 107-120. https://doi.org/10.1093/icb/24.1.107

[74] Blake, R.W. (2004) Fish Functional Design and Swimming Performance. Journal of Fish Biology, 65, 1193-1222. https://doi.org/10.1111/j.0022-1112.2004.00568.x

[75] Schroepfer, R.L. and Szedlmayer, S.T. (2006) Estimates of Residence and Site Fidelity for Red Snapper Lutjanus campechanus on Artificial Reefs in the Northeastern Gulf of Mexico. Bulletin of Marine Science, 78, 93-101. 